\title{
CONSIDERAÇÕES PRELIMINARES SOBRE IDENTIDADE, CLASSE E CAMPESINATO NA ALTA IDADE MÉDIA
}

\section{PRELIMINARY CONSIDERATIONS ON IDENTITY, CLASS AND PEASANTRY IN HIGH MIDDLE AGES}

\author{
Mário Jorge da Motta Bastos ${ }^{1}$
}

\begin{abstract}
Resumo: O objetivo central deste artigo consiste em estabelecer algumas perspectivas teóricas básicas, ancoradas no campo do marxismo, da articulação entre Identidade, Cultura e Classe na História, tomando por contexto específico de referência as sociedades da Alta Idade Média Ocidental. Assim, começaremos por estabelecer as perspectivas marxianas básicas relativas ao conceito de classe, considerando as especificidades da sua aplicação no contexto das sociedades pré-capitalistas em geral. Partimos da proposição da ontologia do filósofo de origem húngara György Lukács, que nos ajuda a compreender a prioridade lógica da classe, como fenômeno objetivo, à tomada da sua consciência que, segundo E. P. Thompson, decorre da experiência histórica das lutas de classe travadas por homens e mulheres reais. Na sequência, visando superar as limitações culturalistas das abordagens correntes da História Cultural propomos, com Gerald Sider, enraizar as manifestações culturais nos processos de produção e reprodução da vida material das classes sociais fundamentais no contexto da transição da Antiguidade à Idade Média, ressaltando como a cultura atua nos processos de dominação e resistência social.
\end{abstract}

Palavras-Chave: História Medieval; Cultura; Campesinato; Hegemonia.

Abstract: The main objective of this article is to establish some basic theoretical perspectives, anchored in the field of marxism, of the articulations between identity, culture and class in history, taking as reference the specific context of the societies of western High Middle Ages. So, we start by establishing the basic marxian perspectives on the concept of class, considering the specificities of his application in the context of pre-capitalist societies in general. We start from the propositions of the ontology of the hungarian philosopher György Lukács, which helps us to understand the logic priority of the class, as a objective phenomenon, in regard with its making that, according to E.P. Thompson, stems from the historical experience of class struggles waged by men and real women. Further, aiming to overcome culturalist limitations of current approaches of Cultural History we propose, with Gerald Sider, to root cultural manifestations in the processes of production and reproduction of material life of the fundamental social classes in the transition from antiquity to the Middle Ages, noting how culture works in the processes of domination and social resistence.

Keywords: Medieval History; Culture; Peasantry; Hegemony.

\section{Introdução}

Permitam-me um ponto de partida que envolve certa dose de ousadia. Para a imensa maioria dos leitores, tanto para aqueles que já se dedicam, de mais ou menos longa data, às temáticas das identidades na História, quanto para aqueles que principiam a explorar as suas possibilidades vasculhando a bibliografia em busca dos seus principais percursos teóricos, arrisco-me a afirmar que o marxismo talvez jamais tenha sido contabilizado como uma via inscrita no rol de possibilidades. Ou seja, dentre as muitas limitações que se costuma atribuir ao marxismo, é possível que uma não menor se expresse, neste âmbito, num certo caráter démodé daquele corpo teórico, sua configuração novecentista que lhe faz anterior, por datação,

\footnotetext{
${ }^{1}$ Professor da Universidade Federal Fluminense. E-mail: velhomario@gmail.com.
} 
ou mesmo simplesmente alheio, por vocação, às temáticas que se tornaram candentes como demandas que mobilizam a nossa contemporaneidade (ou pós-modernidade, para muitos).

E, no entanto, pasmem os senhores e senhoras ao lerem, talvez incrédulos, que a questão da relação entre identidade cultural e classe social constitui um tema clássico no interior do marxismo, constituindo a pedra de toque, por exemplo, do ensaio de Marx intitulado A Questão Judaica (composto por dois escritos redigidos em fins de 1843; MARX, 2003), vindo mesmo a intensificar-se em dois contextos sucessivos: naquele dos debates de fins do século XIX e princípios do XX sobre a questão nacional e, em seguida, no contexto do surgimento do movimento negro nos EUA (apogeu na década de 1960) e das lutas anticoloniais na África, quando a questão racial obrigou também os marxistas a considerarem a relação entre identidade cultural e classe. Por redundante que seja afirmá-lo, a abordagem assumiu matizes bem particulares, dentre eles o caráter pragmático de muitos debates travados, inclusive, no âmbito dos partidos socialistas e comunistas.

Mesmo evocada esta "pequena tradição" no marxismo, a questão da identidade, como atualmente estabelecida, constitui um problema efetivamente novo. Quem nos chama a atenção para o tema é Paulo Gajanigo, com muita perspicácia. A atual configuração do capitalismo vem promovendo uma redefinição dos principais focos do debate nas Ciências Sociais:

O final da guerra fria e a queda do muro de Berlim, somadas à reestruturação produtiva no capitalismo de acumulação flexível, fortaleceu a fragmentação política dos instrumentos de organização da classe trabalhadora. No âmbito dos sujeitos políticos, o enfraquecimento de organizações que reivindicam um projeto socialista, fundamentado numa perspectiva de luta de classes, e o fortalecimento de movimentos e grupos que, orientados por reivindicações diversas relacionadas a aspectos da cultura e da vida cotidiana, deram subsídios para uma narrativa que apontou para o fim de uma história movida pela luta de classes. (GAJANIGO, 2012, p. 25).

Como destacado por críticos diversos, essa foi uma das bases de constituição da perspectiva pós-moderna, que teve entre seus combustíveis a desilusão de teóricos ligados ao campo do marxismo. Descrentes nas possibilidades de enfrentamento global do sistema visando superá-lo na sua totalidade, passaram a se concentrar no potencial transformador de movimentos que têm como base fundamental os elementos diversos da vida cultural. Ainda segundo Gajanigo (2012), essa tendência acabaria por articular os estudos sobre raça, gênero, nação e etnia sob um só tema, o da identidade cultural. Partindo da premissa de que a "classe" estaria privada de qualquer peso efetivo como elemento agregador na política corrente, essa nova perspectiva, que resume todos os sujeitos coletivos às identidades culturais, fez com que a forma de luta política hoje hegemônica tenha passado a ser a da afirmação identitária. Para aqueles que, como eu, acreditam que o marxismo é um corpo de doutrina crítico e aberto, a questão que se coloca para os seus promotores seria: como é possível pensar a classe como sujeito histórico não reduzido a mais uma forma de identidade cultural, sem perder de vista a perspectiva de que a identificação cultural constitui um dos mais fundamentais fenômenos que ocorrem no interior das classes sociais?

O que me proponho a fazer, na sequência deste artigo não é, obviamente, resolver a todas estas questões, mas antes começar a estabelecê-las em suas linhas de força essenciais remetendo-me, ademais, a um contexto que não deve ser, nem de longe, o mais favorável às tentativas que a questão suscita, isto é, a da condição camponesa no contexto da Alta Idade Média (ibérica, em especial). Em primeiro lugar, porque não devo contar com qualquer 
condescendência da parte do(a) leitor(a), já que não há razão para fazê-lo quando se mobiliza, e em especial para o trato com sociedades anteriores às nossas contemporâneas, o referencial teórico que me informa e alimenta. Isso me levará a deter-me, talvez em demasia, em considerações teóricas sem as quais corro o risco de não ter compreendida as bases da minha reflexão.

\section{Classes se identificam na luta}

Ao me referir à questão da identidade de classe, de imediato coloca-se o aparente problema da validade de tal referência em se tratando da sociedade medieval. Considerando a questão com o zelo que aqui é possível, talvez tenhamos, para muitos dos seus críticos, manifesto neste âmbito um dos mais graves pecados cometidos pelo fundador do materialismo histórico, condenando-se Marx por haver generalizado para o conjunto da história humana uma categoria - a de classe - que seria, na melhor das hipóteses, específica da sociedade capitalista. O núcleo crítico desta profanação talvez resida na famosa afirmação do Manifesto Comunista (MARX; ENGELS, 1998, p. 65) a de que a luta de classes constitui o motor da História, fazendo com que toda a História, até aqui, tenha sido a pautada pelas lutas de classes. Mas, não constituirá um evidente paradoxo considerar que um fenômeno que só se realiza como categoria, isto é, só se torne autorreferenciado na sociedade capitalista - as classes sociais possa ser tomado como elemento motor de processos históricos que lhe são cronologicamente anteriores?

São muitas as vias pelas quais poderíamos considerar esta questão. Detenho-me, no entanto, numa proposição de base ontológica segundo a qual o ser social antecede, lógica e historicamente, a sua tomada de consciência.

O processo pelo qual se conhecem os seres sociais é parte do processo em que o próprio ser social se esclarece (desenvolve plenamente suas determinações). Para Marx, as classes não passaram a existir apenas na sociedade burguesa capitalista, como uma criação ex nihilo sua, mas foi nesta que a classe passou a desempenhar um papel central e pôde, portanto, desenvolver-se em todas as suas potencialidades e determinações, permitindo o desvelamento de sua plenitude. (GAJANIGO, 2012, p. 39).

Assim, a possibilidade de que a classe não houvesse, nas sociedades pré-capitalistas, vivido a experiência do seu próprio desvendamento não deve implicar, obrigatoriamente, na inexistência das mesmas naqueles contextos. Não há, como bem entendeu Marx, um processo único, exclusivo, de manifestação das classes na História. "É por isso, inclusive, que não faz sentido lastimar que Marx não tenha avançado numa definição abstrata, formal e atemporal de classe social. Essa iniciativa sim o teria feito incorrer numa generalização anistórica da qual lhe acusam." A distinção fundamental parece residir, comparando-se genericamente aqueles "contextos", na autonomia e plenitude assumidas pelo fenômeno da classe sob o capitalismo, ao passo que, nas sociedades pré-capitalistas, suas "manifestações" se articulam e se expressam no quadro de coletivos e grupos diversos - parentesco, castas, estamentos etc. - , sendo ainda as classes matizadas ali por vínculos de natureza extra-econômica.

O processo de constituição da classe como sujeito envolve, na perspectiva de Edward P. Thompson (2001), dois aspectos fundamentais: a existência de interesses comuns e a 
experiência do confronte de interesses. O primeiro aspecto relaciona-se à determinação objetiva constitutiva do sujeito; o segundo, ao caráter relacional da identidade. Em parte considerável da teoria social contemporânea estes dois aspectos aparecem cindidos:

A preocupação, louvável, de se negar uma caracterização essencialista dos sujeitos sociais tem justificado um destaque para o aspecto da alteridade na constituição do ser social. A perspectiva analítica que isola a alteridade das determinações objetivas dos seres sociais tem encontrado dificuldades em rearticular esses dois aspectos. Para nossa discussão sobre classe e identidades culturais, esse debate assume grande relevância. Com o isolamento desses dois aspectos e a valorização do polo da alteridade, a característica decisiva da classe, isto é, o seu vínculo com o modo de produção, acaba por ver-se esvaziada de toda a sua complexidade. (GAJANIGO, 2012, p. 49).

Mas aí, veja você leitor, acabo de mobilizar outro conceito-chave, envolto em muitas controvérsias, do campo teórico marxista. Mais uma vez, não posso apelar para sua gentil recepção e esperar que admita, sem consternação, o constructo teórico que acabo de mobilizar, sobretudo quando para muitos constitui outro simplismo abjeto dos esquemas marxianos, e aquele que expressaria o seu mais torpe "reducionismo" econômico. Mas será que lidamos, neste nível, de fato com um mecanicismo que reduz o essencial da História às suas determinações materiais? Para um célebre filósofo de origem húngara, György Lukács (2010), a par de outros expoentes do marxismo, a resposta à pergunta é não! O entendimento da questão deve, aliás, mais uma vez, apelar para a premissa da prioridade ontológica, neste caso do "econômico", uma vez que a teoria marxista parte da constatação de que qualquer atividade humana parte de um "chão", um patamar de base, isto é, de um fundamento histórico que inclui a natureza (o meio natural) e as formas de produção e reprodução da vida.

O que se costuma designar por economia é, fundamentalmente, o âmbito ou conjunto de relações por intermédio das quais os seres humanos realizam o seu intercâmbio essencial com a natureza, responsável pelo metabolismo primário intrínseco a sua (nossa) existência. Assim, a prioridade ontológica da economia decorre da primazia da própria natureza na vida humana. Lukács define assim o termo em questão: "Quando atribuímos uma prioridade ontológica a determinada categoria com relação à outra, entendemos simplesmente o seguinte: a primeira pode existir sem a segunda, enquanto o inverso é ontologicamente impossível". (LUKÁCS, 2010, p. 364) É evidente que, para o ser humano, a natureza tem prioridade ontológica, já que sem natureza a existência humana não pode sequer ser imaginada, mas o contrário não é verdade, como bem estabelece o realismo crítico com Roy Bhaskar: a natureza nos dispensa, pois é independente de nós, ainda que "sofra" a ação dos seres humanos. (BHASKAR, 1977) Da prioridade em questão não decorre que o ser humano seja constituído apenas pela natureza, e tampouco nem que sua existência além da natureza - isto é, além deste ato de apropriação fundamental que nos constitui humanos - seja secundária, menos importante ou derivada mecanicamente de uma base.

\section{O Trabalho como fonte da Cultura}

É o trabalho - como processo básico de transformação da natureza segundo as necessidades humanas - que, ainda segundo Lukács (2004), efetiva aquela prioridade 


\section{Notandum 42 set-dez 2016 - CEMOrOC - Feusp / IJI-Univ. do Porto DOI: http://dx.doi.org/10.4025/notandum.42.5}

ontológica do humano, já que é a forma de intercâmbio entre a natureza e a sociedade. É a partir dele que o ser humano se torna social. Marx e Engels, em A Ideologia Alemã, afirmou que:

Pode se distinguir os homens dos animais pela consciência, pela religião ou pelo que se queira. Mas eles mesmos começam a se distinguir dos animais tão logo começam a produzir seus meios de vida, passo que é condicionado por sua organização corporal. Ao produzir seus meios de vida, os homens produzem, indiretamente, sua própria vida material". (MARX; ENGELS, 2007, p. 134).

Do trabalho se pode dizer que potencializou a espécie humana, libertando-a do "reino da necessidade" ao dotá-la de alternativas e do direito de escolha, da liberdade, e impelindo-a a seu caráter essencialmente social para a realização, antes de mais, do fim teleológico da ação humana (atividade que visa a um fim). Mais do que isso, é por meio do trabalho que se configura a forma de relação necessária entre natureza e sociedade. Chegamos assim ao cerne da questão da prioridade ontológica do econômico. O trabalho, quando se realiza, mobiliza elementos indispensáveis como são as ferramentas (tecnologia), por exemplo, e também as relações que os homens tecem ao desenvolver a produção. A este conjunto de condições para a produção material da vida, dá-se o nome de economia. Há, sem dúvida, desdobramentos dessa situação, conexões complexas que só podem ser compreendidas através da análise concreta. No entanto, é importante, no atual estágio do debate acerca da classe, reforçar esse aspecto essencial que não autoriza nenhum determinismo econômico. Assim, os modos de produção são concretos e sua existência pode ser derivada das experiências da vida social (só por isso ele é o modo de produção - a maneira pela qual a vida social é produzida), já que se evidencia pelas condições necessárias da produção e reprodução social.

Avancemos, então, para considerar outro conceito-chave do tema em questão. Nas últimas décadas, o termo cultura se tornou muito popular, e não apenas nos meios acadêmicos. Neste âmbito, uma de suas definições mais usuais, ainda que já estabelecida há décadas, foi elaborada por Edward Tylor, um dos fundadores da antropologia moderna. Segundo o autor, cultura é "aquele todo complexo no qual se inclui conhecimento, crença, arte, moral, lei, costume e quaisquer outras capacidades e habilidades adquiridas pelo homem como membro de uma sociedade" (LARAIA, 2001, p. 75).

Os estudos sobre identidades culturais, no geral, partem dessa concepção ampla e ao mesmo tempo homogeneizadora de cultura. A identidade cultural seria fruto do processo de identificação por elementos relativos a algum destes aspectos da cultura, entendida como modo de vida, hábitos, língua. Deriva desta perspectiva a tendência de que, quando se pensa o conjunto da cultura, exclua-se dele as suas expressões materiais, tomadas algumas vezes apenas como suportes de mitos, ritos e idealidades diversas, além de que comumente se exclua do campo da cultura toda e qualquer manifestação ou expressão da esfera econômica. A cultura chega mesmo a ser definida por oposição à produção material realizada em prol da satisfação das necessidades humanas, ficando assim excluído do seu universo o trabalho, atividade que, como vimos, constitui a sua forma de mediação fundamental.

A produção e reprodução da vida social, no entanto, com a intensificação da divisão social do trabalho, só podem se efetivar pela diversidade dos elementos que mobilizam. Ou seja, as instituições como o direito, ou esferas como a arte, a religião, não estão isoladas da produção da vida social, mas são, cada vez mais intensamente, partes necessárias dessa reprodução. A prioridade ontológica da relação entre a humanidade e a natureza não dá à economia o papel determinante e às outras esferas papel secundário. Em síntese, podemos dizer 
que o mundo do trabalho fornece as condições de existência dessas mediações, mas não as pode resumir. $\mathrm{O}$ fato daquelas esferas se desenvolverem a partir da economia não as torna menos necessárias nem as reduz a um papel acessório ou derivado.

O modo de produção não pode ser identificado, de forma simplista, como apenas um "chão" da vida espiritual:

O modo pelo qual os homens produzem seus meios de vida depende, antes de tudo, da própria constituição dos meios de vida já encontrados e que eles têm de reproduzir. Este modo de produção não deve ser considerado meramente sob o aspecto de ser a reprodução da existência física dos indivíduos. Ele é, muito mais, uma forma determinada de sua atividade, uma forma determinada de exteriorizar sua vida, um determinado modo de vida desses indivíduos. (MARX; ENGELS, 2007, p. 87).

Como propõe Marx, pode se até autonomizar o mundo espiritual do mundo físico, mas as condições de possibilidade daquele dependem desse na medida em que as "espiritualidades" estão inclusive a serviço da produção e reprodução da vida social. Portanto, a dinâmica do conjunto da cultura não deriva de uma determinação externa da vida material. Será possível identificar essa dinâmica se olharmos para o modo como a vida social é produzida e reproduzida.

Por isso, em outro momento (BASTOS, 2013), dediquei-me a refletir sobre a cultura camponesa medieval baseando-me na indissociável articulação entre os saberes e os fazeres campesinos medievais, vendo aí o cerne da identidade medieval deste sujeito histórico por excelência de um conjunto de sociedades que designamos por pré-capitalistas. Sociedades caracterizadas, todas, pelo predomínio generalizado do que chamamos atualmente de setor primário da economia, quando a imensa maioria da população - algo em torno a $95 \%$ dela, por exemplo, mesmo nas regiões que estiveram na linha de frente do mal designado renascimento urbano do século XI no Ocidente medieval - vivia não só radicada no campo como orientada pela produção para consumo direto (produção de valor uso). Fundamentadas em um processo de produção organizado e reproduzido no âmbito da família e da comunidade, as aldeias campesinas articulavam-se, portanto, por relações sociais de cunho familiar e local que se impunham como uma base estável e tradicional de existência.

Sociedades hierarquizadas e cindidas na sua imensa maioria (pelas clivagens decorrentes da submissão ao poder senhorial e das próprias hierarquias aldeãs), a condição essencial da existência nestas sociedades pré-capitalistas envolveu a articulação entre produção camponesa - sob formas de organização da produção diversas, marcadas por níveis também distintos de autonomia produtiva e sujeição social - e extração de excedentes por elites dominantes também diversas que se destacaram, contudo, por sua ascendência e pelos níveis de controle variados que impuseram aos campesinatos. Assim, o binômio autonomia/sujeição determinou, em grande parte, as estruturas, relações, quadros de existência e de vida cotidiana camponesa nestas várias sociedades, bem como sua identidade e cultura, circunscrevendo um longuíssimo percurso histórico em meio ao qual é possível discernir elementos estruturantes que pautam a diversidade de seus matizes.

Aqui me parece residir o aspecto fundamental, o cerne da apreensão da identidade e da cultura camponesa na Alta Idade Média. O trabalho foi e é o processo essencial da constituição dos seres humanos em sua historicidade, porque é ao mesmo tempo a base crucial da articulação indissolúvel, em cada um de nós como membros da espécie, do "saber" e do "fazer", e 
mecanismo fundamental de ocultação e de fetichização que sustenta todos os sistemas sociais fundados na exploração.

Assim, a condição lógica e histórica fundamental, porque primária, de todo desenvolvimento cultural humano é o saber produtivo que está na base de nossa existência e reprodução. Mas porque os campesinatos surgiram, historicamente, como resultantes de complexos processos de fratura, diferenciação e desigualdade social que cindiram as comunidades humanas, o trabalho da terra redundou em forma de especialização e expressão da divisão do trabalho social em condições gerais de subalternização. Foi essa diferenciação histórica que, ademais, também em graus diversos, promoveu as especializações que cindiram a unidade primária e essencial existente entre os "saberes" e os "fazeres", entre trabalho manual intelectual e trabalho manual, constituindo os primeiros como entidades superiores, exclusivas e verdadeiras manifestações do intelecto humano, e os segundos como funções menores, carentes de intelectualidade e desqualificadas em graus e por razões diversas. Esse quadro foi, de certo, ainda mais distintivo nas sociedades pré-capitalistas, em que os processos de produção eram, em grau bastante elevado, dominados e dinamizados pelos próprios produtores diretos.

\section{Cultura e Classe Social}

Orientado pela perspectiva da constituição de uma antropologia histórica de inspiração marxista, Gerald M. Sider (2003) propõe-se a refletir sobre a natureza do paradoxo que crê configurar a abordagem da cultura em ambas as disciplinas, particularmente no que tange à sua inserção nos processos de mudança social. Por um lado, destaca que há no interior do marxismo um conceito de classe que é relacional, processual e específico. Nesta perspectiva, qualquer classe social particular só se define e compreende na sua relação com outras classes sociais, com as forças materiais de produção, e com as relações de propriedade que embasam a criação, a transferência e a transformação dos excedentes. O conceito é, portanto, essencialmente dinâmico, focando a análise na forma sócio-estrutural que gera processo: as contradições entre a forma de propriedade e as capacidades e necessidades dos produtores. Por outro lado, e comparativamente, o conceito antropológico de cultura - concebido tanto como valores partilhados quanto como um sistema de valores, crenças, símbolos e rituais - padece da ausência de um cerne dinâmico e processual.

Dada a inexistência de uma estrutura dinâmica própria, ou ao menos de alguma que possamos ver e compreender, a cultura tende a ser expressa como um epifenômeno, derivada e secundária, como uma superestrutura constrangida e mecanicamente submetida às determinações de uma base econômica. Além disso, isenta de uma estrutura dinâmica que especifique o que é, e na extensão o que não deve ser, cultura, esse conceito assume muitas vezes um caráter amorfo, vago e totalizante, em pelo menos dois sentidos. Primeiro, porque tudo é passível de tornar-se, ou de ser concebido, como cultura, como nas referências à cultura simbólica, à cultura ritual, à linguagem como cultura, valores, crenças, idéias, ideologias etc. Segundo, não apenas tudo ou quase tudo numa sociedade é cultura, como o seu teor totalizante se reforça pela perspectiva de que todos tenham, numa sociedade, uma mesma cultura segundo o conceito de cultura como valores partilhados - ou de que ao menos possam ser avaliados por seus distintos padrões, obviamente em relação ao que se define como norma, como no conceito de privação cultural ou na noção de subcultura.

Em suma, o paradoxo a que se refere o autor consiste nesta espécie de dubiedade. Totalizante, a cultura afirma-se como independente, um aspecto ou abstração do sistema social aparentemente não conectado a outros aspectos ou abstrações. E, contudo, não sendo o conceito nem processual nem dinâmico, a cultura aparece como derivada das estruturas que expressam 
mais claramente o movimento. As dificuldades manifestam-se e atingem tanto os especialistas vinculados quanto os alheios aos referenciais marxistas de análise. Clifford Gertz, por exemplo, afirma que "a cultura é 'independente', mas interdependente em relação à organização social." (SIDER, 2003, p, 35) Por outro lado, no interior do marxismo, o tema é essencialmente abordado sob o prisma das relações entre a base e a superestrutura, propondo-se que a primeira seja determinante, ao menos em última instância, ou que haja uma interação dialética entre ambas. Mantém-se, portanto, essencialmente, em aberto a questão: será possível considerar como, e por que, a cultura tem, ou pode ter, sua própria dinâmica histórica, ao menos parcialmente independente, e poder-se-á configurar a extensão pela qual a cultura é determinante, determinada ou irrelevante em um contexto de relativa transformação das condições da vida cotidiana e das relações de produção?

Não é possível, afirma Gerald Sider, encaminhar uma alternativa a tal questão buscando-se tão somente reformular o conceito antropológico de cultura, como que para tornálo mais específico e dinâmico. Por seu turno, o conceito de classe padece, via de regra, de suas próprias limitações justamente por desconsiderar aspectos cruciais da vida social destacados pelo conceito de cultura. Convém, portanto, indicar as alternativas para um possível emprego dos dois conceitos por esta via de abordagem. Quanto ao conceito de classe, o seu uso apropriado deve distinguir, em primeiro lugar, duas diferentes acepções, relacionadas a contextos históricos específicos aos quais se aplica. Segundo Eric Hobsbawn, "sob o capitalismo a classe é uma realidade imediata e em certo sentido diretamente "experimentada", ao passo que em épocas pré-capitalistas não pode ser mais que uma construção analítica que dá sentido a um complexo de dados de outro modo inexplicáveis." (THOMPSON, 1979, p. 36)

Deveríamos nos guardar, portanto, sobretudo ao empregá-la como uma categoria heurística, cuja correspondência empírica é muito menos direta, de projetar sobre as sociedades anteriores à Revolução Industrial uma notação de classe que não era acessível ao sistema cognitivo dos seus próprios indivíduos. Contudo, que a formação de classes "plenas" corresponda ao advento de um modo de produção específico não implica que o que se expressa de forma menos decisiva não seja classe. Além disso, não é possível considerá-la como uma categoria estática, o que supõe uma derivação mecânica de classes que surgiriam, imediatamente, das próprias relações de produção, desconsiderando-se as relações sociais de mais amplo teor nas quais estas se inserem:

As classes "acontecem" ao viverem, os homens e as mulheres, suas relações de produção, e ao experimentarem suas situações determinantes, dentro de um conjunto de relações sociais, com uma cultura e expectativas herdadas, e ao modelarem estas experiências em formas culturais. De modo que, enfim, nenhum modelo pode nos proporcionar o que deve ser a "verdadeira" formação de classe em uma determinada "etapa" do processo. Nenhuma formação de classe propriamente dita da história é mais verdadeira ou real que outra, e classe se define a si mesma em seu efetivo acontecer. (THOMPSON, 1979, p. 36).

Um último aspecto a considerar diz respeito à centralidade das noções de contradição e luta de classes nas análises marxistas, que, levadas ao extremo, implicam na extrema rigidez com que se delineiam os sistemas de classe, tidos como essencialmente fundados na oposição entre elementos antagônicos (trabalhadores e proprietários, trabalho e capital etc.). Uma análise mais sutil destes sistemas indica frequentemente a impossibilidade da demarcação de qualquer fronteira rígida e permanente, separando grupos ou campos antagônicos. Isso significa que os 
processos históricos que têm lugar no interior de uma classe - as suas potenciais e efetivas alianças e oposições - são tão fundamentais como as lutas entre classes, levando-as a definirse, portanto, na história, e não apenas nas relações de produção:

É neste ponto que a cultura entra na dinâmica da classe, e menos porque a cultura "acontece" no interior das classes e das lutas entre classes. A cultura penetra a dinâmica da classe porque é o locus no qual a classe se torna dinâmica, onde oscilam, unem-se e separam-se as suas linhas de antagonismo e aliança. (SIDER, 2003, p. 8).

Mobilizei este conjunto de referências para destacar a importância da cultura nos processos de dominação e resistência social, ou seja, a importância da cultura nas manifestações de classe e, em especial, nos contextos marcados pela intensificação das lutas de classes. Assim, no contexto da transição da Antiguidade à Idade Média no ocidente, a progressiva redução do campesinato livre às relações de dependência, a sua submissão a uma aristocracia fundiária cuja reprodução material dependia de mecanismos diversos de extração dos excedentes campesinos envolveu manifestações variadas de conflitos sociais. Em meio a tantas formas de resistência múltiplas, que papel podemos atribuir às expressões culturais naquele processo?

Segundo Pierre Dockès, o

campesinato livre e amiúde solidamente agrupado em comunidades rurais aglutinava-se com base em práticas de trabalho (...), mas também por práticas culturais. Esta cultura camponesa da Alta Idade Média é caracterizada, negativamente, por sua resistência ao cristianismo, (...) [e] positivamente pela herança do paganismo autóctone, e até, talvez, por práticas transmitidas pelos escravos. Essa herança pagã afirma-se nas festas (solstício de inverno coincidindo com o Natal, a festa de solstício de verão com as fogueiras de São João, banhos rituais, celebrações noturnas, danças, cantos), práticas consideradas obscenas pela Igreja e por ela perseguidas vigorosamente. (DOCKÈS, 1984, p. 123).

Considerações como essa se, por um lado, merecem todo crédito por ampliar o nosso campo de visão dos fenômenos em questão, por outro perdem de vista a progressiva participação camponesa na visão de mundo cristão que se vai afirmando nos primeiros séculos medievais. Se o locus fundamental da conversão cristã da Alta Idade Média residiu nas comunidades locais, aldeias e senhorios, e se este processo manifestou-se, sobretudo, no "nível da cultura", parece necessário considerar que a autonomia da cultura aldeã, assim como a das relações sociais aldeãs, talvez fosse parcial em dois sentidos fundamentais: o da limitação decorrente da pressão senhorial e o da relação - em confronto ou associação - com as forças de dominação que se lhe impunham. A consideração deste tópico depende, contudo, de que se busque uma alternativa ao conceito idealista de cultura correntemente adotado nas abordagens, como já destaquei.

Seja qual for a sua utilidade quando se aborda grupos de caçadores-coletores, ou sistemas sociais relativamente igualitários, ele não me parece muito adequado à abordagem de sociedades de classe. Em situações de conflito de classe, a noção de valores partilhados pode servir apenas de ponto de partida para um conceito mais específico, visando à compreensão tanto da imposição da hegemonia cultural das classes dominantes quanto à formação de culturas 
em confronto. Como não se trata de negar a importância da cultura nos processos sociais, recorro, então, a um conceito que supere as definições centradas no seu conteúdo e que busque estabelecer uma efetiva correlação entre cultura e relações sociais. Proponho que a base da cultura, e da religião como campo primordial de sua manifestação, reside na forma e na maneira pela qual os indivíduos entendem, definem, articulam e expressam as mútuas relações estabelecidas entre si e com a natureza. Em sociedades caracterizadas por uma profunda hierarquização e apropriação desigual da produção, estas formas de percepção social e modos de comportamento fundamentam-se tanto nos aspectos relativamente igualitários da organização do trabalho e da vida quotidiana, e na reprodução deste domínio ao longo do tempo, quanto na extrema desigualdade que caracteriza a relação de apropriação do produto e a reprodução dessa relação. (SIDER, 2003, p. 120)

O conceito marxista de produção destaca a profunda articulação existente entre a organização do trabalho e a apropriação de seu produto e, de fato, sob o capitalismo, a própria organização do trabalho reproduz formas de domínio e controle. Mas, talvez nem mesmo sob este modo de produção uma tal conexão, ainda que muito estreita e sólida, seja total. E nas formas pré-capitalistas de organização social e produtiva, nas quais as comunidades e/ou famílias são o âmbito da organização do trabalho, a conjunção entre este e a apropriação é feita através de múltiplas e diversas conexões. (MARX, 1971, I, p. 449) Visando caracterizá-las, mas inclusive suas defasagens e contradições, recorro ao conceito gramsciano de hegemonia (GRUPPI, 1980), essencial à abordagem da cultura sob a perspectiva da compreensão dos fenômenos de dominação e resistência. Assim como não atribuo à cultura um caráter "totalizante", não considero a hegemonia capaz de penetrar a consciência até o nível do senso comum, impondo-lhe categorias insuperáveis de subordinação. Se a autonomia relativa da cultura reside no seu embasamento em diversas estruturações da ordem social, concebo a hegemonia como aquele aspecto da cultura que, na presença do conflito ou da oposição, visa mais diretamente unificar o trabalho e a apropriação, estendendo-a além do trabalho, para o interior da família, da comunidade e, enfim, para a própria vida cotidiana das classes trabalhadoras. (SIDER, 2003, p. 119-128). Mesmo em se tratando da reprodução ampliada das relações de produção capitalistas, Karl Marx destacou o "dever" dos trabalhadores de "respeitar o produto do [seu] trabalho, e o [seu] próprio trabalho como valores pertencentes a outros" (MARX, 1971, I, p. 104-105), o que não se produz automaticamente no local de trabalho, mas deve ser constantemente recriado e reforçado pela combinação de pressões políticas, econômicas e culturais.

É uma tal combinação, particularmente íntima em se tratando das sociedades ocidentais europeias da Idade Média, que determina a estrutura característica da hegemonia. Particularmente reveladora, a esse respeito, é a extrema difusão assumida pelo vocabulário básico relativo às relações de dependência pessoal nas fontes do período. Se entendermos a hegemonia como uma efetiva afirmação dos valores e demandas da elite, enraizando-se na organização social da apropriação e reforçando o seu vigor pela articulação entre símbolos culturais e a reivindicação do produto do trabalho, talvez seja possível considerar a quase ubiquidade de alguns dos referentes culturais críticos na sociedade altomedieval - dominus, famulus, servi, patronus, fidelis, servitium - recorrentes nas leis, fórmulas notariais, atas conciliares, liturgia... Mais do que vínculos fortuitos, ou imprecisão vocabular, tais expressões articulam os "campos" da religião, da cultura, da política, da economia, relacionando-os ao mundo material e espiritual em geral e a "formas de propriedade" em particular, e assim, implicitamente, a relações sociais antagônicas, sugerindo que no bojo da concepção de cultura como "valores partilhados" manifestam-se, de fato, fenômenos de classe específicos. 


\section{Considerações Finais}

Não pretendo reintroduzir, na abordagem do tema, por um tal viés de análise, qualquer premissa de uma ação maniqueísta, racional ou deliberadamente orientada por parte das elites visando a submissão ou a imposição do seu domínio sobre o campesinato. Mesmo porque isso o reduziria à condição de passividade, quando de fato essas comunidades demonstraram um enorme vigor criativo que suscitou a reação e as tentativas de controle da hierarquia. Assim, a religião e a cultura partilhadas no período, dado o intercâmbio dialético que mantiveram com as relações sociais, constituíram-se em elementos de afirmação do status e das pretensões das elites aristocráticas, atuando, portanto, em prol da afirmação de sua ascendência social. Se a religião consistiu no efetivo "fait total" da Idade Média, impõe-se considerá-la no fluxo das relações sociais, na dinâmica de seu curso e evolução na sociedade do período, na tentativa de vislumbrar suas articulações essenciais. Quanto a essas, decorreram da conjugação de dois processos, ou, antes, da intrínseca articulação que os vinculou, o da transformação das relações de produção, das formas do exercício do poder e da dominação em uma sociedade marcada pela expansão do regime senhorial, e o da implantação e expansão do cristianismo.

Em que pese a acentuada redução da autonomia camponesa decorrente do vertiginoso processo de expansão do senhorio, tal sistema, ainda que se tenha caracterizado pela progressiva afirmação da ascendência senhorial como vértice articulador das relações comunitárias, nas villae e aldeias, não suprimiu, contudo, a íntima relação entre o produtor e os meios essenciais de produção e reprodução das suas condições de existência. Longe de se constituírem em força de trabalho desprovida de meios, as unidades familiares satisfaziam as demandas fundamentais da sua própria subsistência, preservando um certo grau de autonomia e controle das condições materiais e ideais da produção.

Quanto a esta, situam-se no seu cerne as relações estabelecidas pelos homens entre si e com a natureza, imbuídas de uma parte ideal por meio da qual estas mesmas relações são representadas, organizadas e legitimadas, "função" essencial exercida pela religião no período. Considerada a perspectiva básica da conversão do mundus, vislumbra-se a orientação cristã de recobrir com o seu referencial as várias atividades e temporalidades que lhe ritmam a existência. Era este o âmbito essencial em que o cristianismo, contatando uma ordem sagrada prévia, buscou reordenar o conjunto das relações sociais, inserindo-se em meio a todas as atividades cotidianas das populações.

A concepção fundamental (BASTOS, 2013) da cosmovisão cristã senhorial reside no caráter atribuído à divindade e na natureza das suas relações com o conjunto da obra da Criação. Concebido como um Dominus, Senhor e Reitor do Universo, a vida humana decorre de uma dupla e complementar manifestação do poder divino. Fundada em um vínculo original, pessoal e direto, reafirmado no pacto celebrado no batismo, não há um nível, um sentido, geral ou específico das relações sociais que não suponha uma ativa ascendência e intervenção divina, vértice senhorial supremo ao qual se faz convergir toda a comunidade. Assim, os atos e atividades cruciais da vida cotidiana decorrem da proteção, da piedade e dos presentes graciosos do Deus único, misericordioso e vindicativo.

Senhor provedor, de sua benéfica intervenção origina-se o milagre da reprodução das sementes, a chuva restauradora e fertilizante, a chama do fogo doméstico que aquece e protege a casa até que a face serena do Pai se manifeste refletida no brilho do astro matutino. Transgredida a sua lei, do seu poder de mando ultrajado decorrem as fomes, as epidemias e as pragas devastadoras, sanções que visam à reparação, o restabelecimento do sentido correto da relação por intermédio do apelo do ínfimo dependente à misericórdia do poderoso. Toda a ordem, ou a momentânea desordem, que rege o Universo decorre da manifestação de um poder 
único, restrito, e concentrado, acessível apenas através da intermediação de seus representantes terrenos. Homem e natureza, criaturas divinas, partilham a mesma condição, isto é, são alheios a qualquer virtude intrínseca, que não decorram de uma concessão superior. Tornada passiva, privada de suas forças misteriosas, ou reduzidas estas à ação diabólica, a identidade entre homem e natureza insere-se no âmbito das relações de dependência. Esta já não é diretamente acessível, material e idealmente, uma vez que o contato com o poder superior que lhe controla prevê o recurso aos indispensáveis vínculos sociais de submissão e deferência. Foi a conversão primária da aristocracia e o seu controle dos postos-chave da Igreja que fez do cristianismo a forma de sua expressão de classe, de sua posição na hierarquia social; de seu domínio derivaram as formulações sacras que vincularam o Céu e a Terra no contexto geral de dominação social.

Mas tais preceitos não "encerram toda a história", assim como a afirmação do poder jamais se efetua alheia à dialética da sua contestação. Apesar dos limites impostos pela natureza das fontes disponíveis, as sucessivas condenações de crenças e práticas contraditórias com a ortodoxia cristã parecem revelar que a relativa autonomia preservada pelas comunidades camponesas sustentaram uma base de contínua elaboração e reelaboração de uma cosmovisão irredutível, plenamente, aos preceitos ditados pelas elites eclesiásticas. Numa época em que os sacerdotes cristãos se requisitavam, e impunham pela força, com o apoio do "braço secular", o exclusivo da mediação com os céus, o campesinato preservou, assim, de alguma forma e por vias que nos escapam em sua plenitude, centros de ascensão por intermédio dos quais era ainda possível um contato pessoal e direto com o sagrado.

\section{REFERÊNCIAS}

BASTOS, M. J. da M. Assim na Terra como no Céu: Paganismo, Cristianismo, Senhores e Camponeses na Alta Idade Média Ibérica (Séculos IV-VIII). São Paulo: Edusp, 2013.

BHASKAR, R. A Realist Theory of Science. London: Verso, 1977.

DOCKÈS, P. La Liberación Medieval. México: Fondo de Cultura Económica, 1984.

GAJANIGO, P. R. Identidade cultural e consciência de classes no capitalismo tardio. 2012. 169f. Tese (Doutorado em Serviço Social) - Universidade Estadual do Rio de Janeiro, Rio de Janeiro, 2012.

GRUPPI, L. O Conceito de Hegemonia em Gramsci. Rio de Janeiro: Editora Graal, 1980.

LARAIA, R. de B. Cultura: um conceito antropológico. Rio de Janeiro: Jorge Zahar Ed., 2001.

LUKÁCS, G. Ontologia del ser social: el trabajo. Buenos Aires: Herramienta, 2004.

. Prolegômenos para uma ontologia do ser social. São Paulo: Boitempo, 2010.

MARX, K. Elementos fundamentales para la crítica de la economia política (borrador), 1857-1858, vol. I. Buenos Aires: Siglo XXI, 1971.

. A questão judaica. São Paulo: Centauro, 2003. 
. A ideologia alemã. São Paulo: Boitempo Editorial, 2007.

MARX, K.; ENGELS, F. Manifesto do partido comunista. In: D. Aarão (org.). O manifesto comunista 150 anos depois. Rio de Janeiro: Contraponto, 1998.

SIDER, G. M. Between History and Tomorrow: Making and Breaking Everyday Life in Rural Newfoundland. Canada: University of Toronto Press, 2003.

THOMPSON, E. P. Algumas observações sobre classe e 'falsa consciência. In: NEGRO, A. L.; SILVA, S. (Orgs.). As peculiaridades dos ingleses e outros artigos. Campinas: Unicamp, 2001.

Tradición, Revuelta y Consciencia de Clase. Barcelona: Crítica, 1979. 